\title{
Relationships between the presence of odonate species and environmental characteristics in lowland ponds of central Italy
}

\author{
G. Carchini ${ }^{1 *}$, V. Della Bella ${ }^{2}$, A.G. Solimini ${ }^{1}$ \& M. Bazzanti ${ }^{2}$ \\ ${ }^{1}$ Department of Biology, University 'Tor Vergata', Rome, Italy. \\ ${ }^{2}$ Department of Animal and Human Biology, University 'La Sapienza', Rome, Italy
}

\begin{abstract}
A set of 21 ponds was sampled three times for odonate larvae during spring 2002. At the same time 17 environmental variables were recorded including area, wet phase duration, total nitrogen, total phosphorus, aquatic macrophytes and land use. A total of 16 odonate species belonging to Lestidae, Coenagrionidae, Aeshnidae and Libellulidae were recorded, and the total number of species per pond varied from zero to six. The relationships between species richness, assemblages and environmental variables were studied by simple and multiple correlation and by Canonical Correspondence Analysis (CCA). The results showed that permanent ponds were larger, deeper, had more macrophyte species, had more extensive macrophytes cover and lower concentrations of nitrogen and phosphorus than temporary ponds. Multiple regression analysis showed that the number of odonate species was positively affected firstly by the number of macrophyte species, and then by pond depth. However, pond depth appeared to be interchangeable with several others variables, such as pond area and water duration and negatively correlated with nitrogen concentration, variables which are all linked with the permanent or temporary status of the ponds. CCA analysis indicated that odonate species presence was linked with a few environmental variables, showing a tendency of Odonata to avoid ponds with higher nitrogen concentrations, with the exception of Lestes barbarus, a species typical of temporary water in central Italy. At the same time, the majority of species were linked with longer water phase duration and with greater macrophyte species richness. A comparison with previous studies, and in particular with those carried out in central Italy, confirmed the positive influence of macrophytes, water duration, and also the negative effect of nutrient load. However, several other variables, in particular land use, shade, presence of fish, which were influential in other studies, were not significant in this study.
\end{abstract}

Keywords: Odonata, permanent and temporary ponds, macrophytes, nitrogen.

\section{Introduction}

Odonate species are particularly abundant in ponds, where their larvae are among the most important predators. In fishless ponds, they can even be at the top of the food chain. Despite the fact that all Odonata are predators both at the larval and adult stage, they show quite a large differentiation in several life cycle features, such as oviposition, egg and/or larval diapauses, microhabitat preference, lifespan of the larvae and adults, and so on (reviewed in Corbet 1999). Several species are limited to permanent waters, while some can also breed in temporary waters. Their geographical distribution is usually on a regional scale or larger, with only a few species endemic to restricted areas. Their presence in a water body, and specifically in a pond, is mainly due to ecological conditions. For these reasons, Odonata are often chosen among macroinvertebrates as indicators of the ecological conditions of ponds

\footnotetext{
*Corresponding author: E-mail: carchini@uniroma2.it
}

(Godreau et al. 1999, Briers \& Biggs 2003). While several studies have been published on the relationships between environmental variables and odonate species occurrence in still waters, there are fewer studies in which temporary waters have also been considered. Furthermore, species with a large geographical distribution appear to be able to adapt to different ecological conditions (Sahlén \& Ekestubbe 2001). Therefore it is of interest to carry out studies in different geographical areas and, in particular, in the Mediterranean regions, where many ponds are temporary due to the long arid summers. The aim of this paper is to assess the relationships between Odonate species presence and habitat characteristics in a set of permanent and temporary lowland ponds in central Italy.

\section{Materials and methods}

Twenty-one ponds were chosen in the coastal area between Rome and the Tyrrhenian Sea, all located at low elevation ( $<100 \mathrm{~m}$ a.s.1.). The ponds were located 
in four nature reserves, in some cases surrounded by old woods and in others by pastures or meadows, and isolated from each other and from other surface waters. A detailed description of pond locations and of their management regime was reported in Della Bella et al. (2005). Although the surveyed ponds were already known to be permanent or temporary, water presence was checked from autumn 2001 to autumn 2002. All macroinvertebrates were sampled in March, May and June 2002, in distinct mesohabitats (sensu White \& Irvine 2003), i.e., emergent and submerged aquatic vegetation, littoral and central sediments. A pond net with $0.28 \mathrm{~mm}$ mesh was used, working over replicates of 1 meter (1-4) in proportion to the surface area of the pond. The sampling procedures were described in detail by Della Bella et al. (2005) and by Solimini et al. (2005). Odonata were fixed and conserved in $10 \%$ formalin and were identified in the laboratory to species level, except for small individuals which were only identified to family level. Odonate species identification was made following Carchini (1983) and by referring to material from Carchini's collection. In the coastal area of Rome both Chalcolestes viridis viridis (Vander Linden) and $C$. viridis parvidens (Artobolevski) are present. Even if according to Cobolli et al. (1994), these taxa should be separated into two valid species, they are impossible to distinguish in the larval stage (Carchini, personal observation). Consequently, in the present study we considered all individual as Chalcolestes viridis (Vander Linden). An odonate taxon was considered present if at least one larva was found in a sample. The records of all samples were pooled to obtain a matrix of species $\mathrm{x}$ pond presence-absence data.

Seventeen environmental variables were recorded, both from the pond and their surroundings, and a detailed description of the procedures and laboratory methods used is reported in Della Bella et al. (2005) and in Solimini et al. (2005).

Simple correlations between pairs of variables were assessed by Spearman rank correlation test. Multiple regression analysis was performed in which the dependent (response) variable was the number of odonate species and the independent (predictor) variables were habitat characteristics. As many of those predictor variables were dependent on each other, we chose the forward stepwise procedure, which includes one new explanatory variable at each step, specifically the one most associated with the response variable while being, at the same time, independent of the explanatory variables already included in the model. The criteria to include or exclude the variables from the regression model were: entry criterion $F \geq 4.0$, remove criterion $F<4.0$. The number of species and all the habitat variables (except those expressed as percentages or presence-absence) were log transformed. A Canonical Correspondence Analysis (CCA) was performed in which the first matrix was made by the presenceabsence of all odonate species, including a "zero species" variable in order to also take into consideration the ponds without Odonata, and the second matrix was made by the environmental variable values. Again, the variables were $\log$ transformed, with the exception of those expressed as percentages or presence-absence. CCA was done with The Vegan Package (available at http://www.r-project.org/), a contributed package for the $\mathrm{R}$ environment. The data on small larvae identified at family level were not included either in the multiple regression or in the CCA analyses.

\section{Results}

A summary of the results on odonate presence and environmental variables values is presented in Table 1 . The CCA analysis performed first with all environmental variables gave nonsignificant results in the linkage between the two matrix at 1000 permutations test. A second analysis with a reduced set of environmental variables gave significant results shown in Fig. 1.

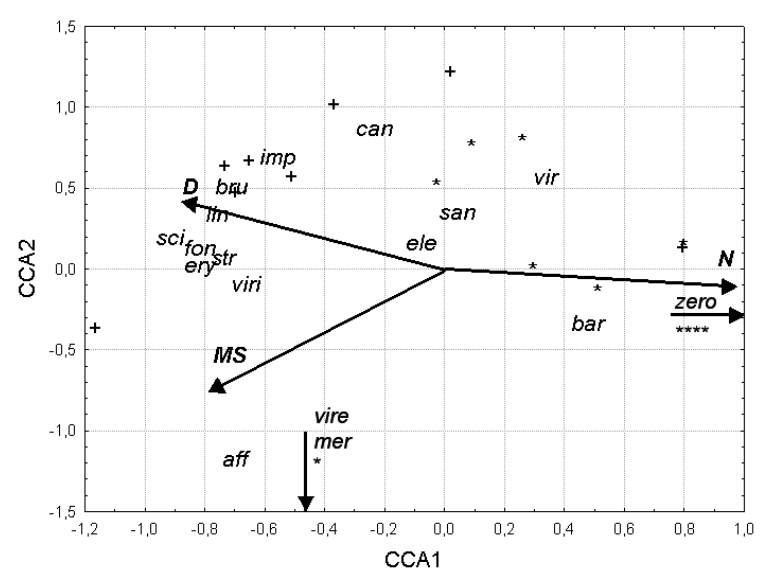

Fig. 1. Canonical Correspondence Analysis biplot of presenceabsence data of odonate species and habitat variables recorded in 21 ponds in central Italy. The odonate species are represented by codes, the habitat variables by codes and vectors, whose length is proportional to the weight of that variable in the overall ordination. Codes are explained in Table 1. The permanent ponds are represented by crosses, the temporary ones by stars. The arrow on the right hand side of the drawing indicates the positions along the first axis of four temporary ponds (****) and of the zero odonate species point (zero). The arrow in the lower part of the drawing indicates the positions along the second axis of two species (vire and mer) and of one temporary pond (*). Not all environmental variables were considered in this CCA output. 


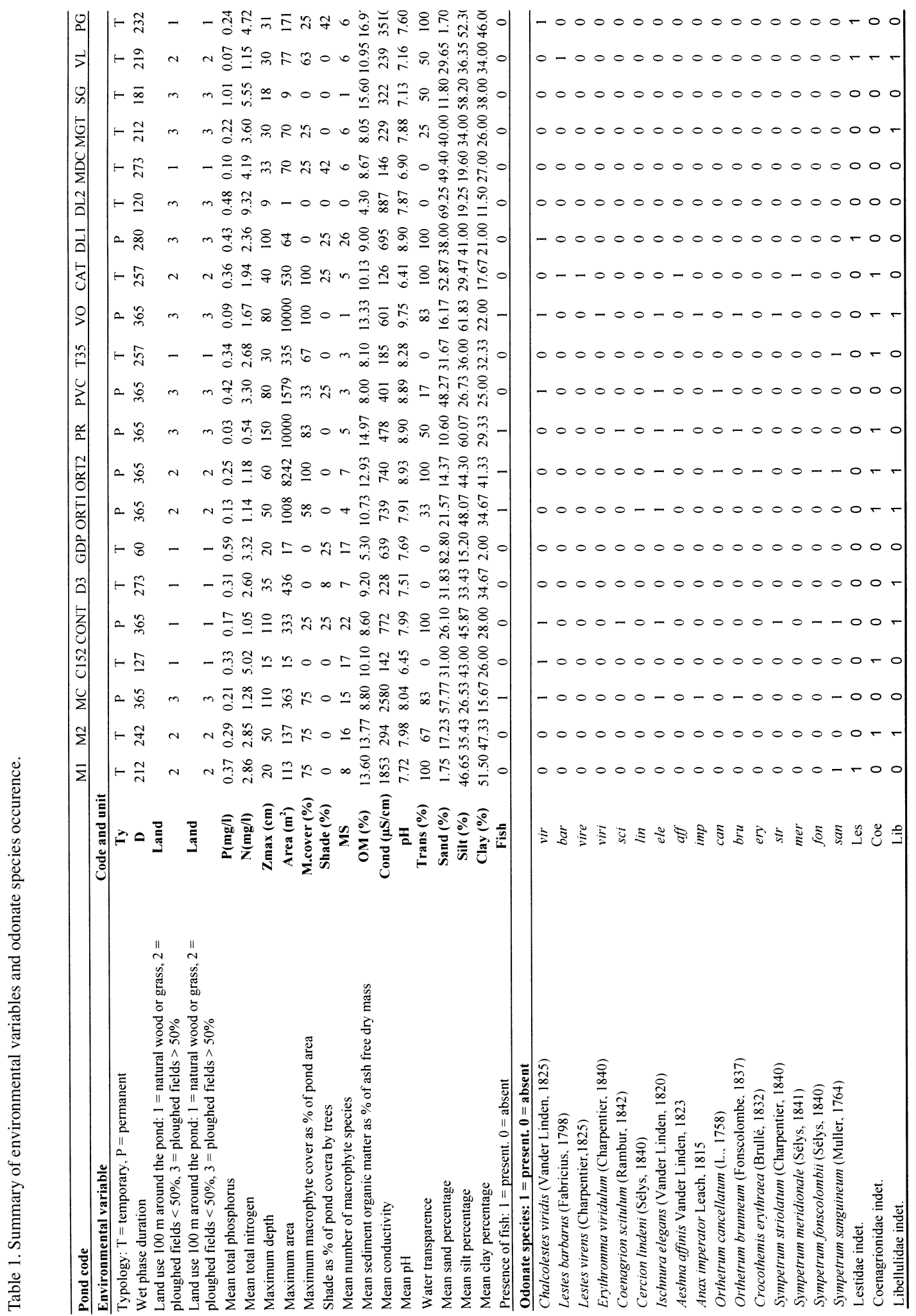




\section{Pond characteristics}

Thirteen ponds were dry in November 2001 and again in July 2002 but wet for different periods between these two months, and were considered as autumnal temporary ponds (sensu Wiggins et al. 1980). Seven ponds were wet in November and retained water until the next autumn. One pond (DL1), already known to be permanent, was wet in November but dried up after the last sampling in June. We decided to consider the latter as permanent because drying up affected the next generations of odonate species, rather than those recorded in the present study. Results in Table 2 shows that, in our set of ponds, the duration of the wet period (D) was positively linked to both area (Area) and depth (Zmax). The area was, in turn, positively correlated with both depth and number of macrophyte species (MS), while area, depth and macrophyte species richness were all negatively correlated with total nitrogen concentration (N). The CCA results (Fig. 1) show that six out of eight permanent ponds were on the negative part of the first axis along the increasing gradient of macrophyte species number (MS) and water duration (D), while 9 out of 14 temporary ponds were in the positive part of the first axis along the increasing gradient of nitrogen concentration (N). Despite a small overlap in the two pond type, differences can be seen between temporary and permanent ponds along the nitrogen concentration gradient, the water phase duration and the number of macrophyte species.

Table 2. Spearman rank correlation coefficient for significant variables. The probability values were adjusted with the Bonferroni correction for multiple results. Variables codes are shown in Table 1.

\begin{tabular}{llll}
\hline Pair of variables & $\mathrm{n}$ & Spearman $\mathrm{R}$ & $P$-level \\
\hline Area vs Zmax & 21 & 0.772 & 0.006 \\
Area vs D & 21 & 0.748 & 0.015 \\
Area vs MS & 21 & 0.755 & 0.012 \\
Area vs N & 21 & -0.565 & 0.009 \\
Zmax vs D & 21 & 0.803 & 0.002 \\
Zmax vs N & 21 & -0.777 & 0.005 \\
MS vs N & 21 & -0.732 & 0.025 \\
\hline
\end{tabular}

\section{Number of odonate species}

A total of 16 odonate species were identified overall and the maximum number of species in each pond was six, the mean value being 1.95 (S.D. = 2.16). A total of seven ponds had no odonate species and, excluding these, the mean number of odonate species rose to 2.9 (S.D. = 2.02). In several ponds the number of odonate species would have been higher if the presence of small specimens had been included. In fact, in some cases small specimens were collected which belonged to a family of which no large specimens were identified to species in that pond (i.e. M1, where the Libellulidae were represented by Sympetrum sanguineum (Müller), but the Lestidae only by small specimens). However, the lack of large larvae in ponds where small ones were identified suggests that the unidentified species were unable to complete their larval growth. In particular, small Coenagrionidae were collected in five temporary ponds, but only in the May or June samplings. In this case, it is possible that these individuals came from ovipositions of some early emerging species (such as Ischnura elegans (Vander Linden), which we observed reproducing as early as March in favourable years) that tried to colonize ponds where the larval development cannot be completed. For these reasons, we decided not to take into consideration the family level data in the analyses.

Table 1 shows that all the eight permanent ponds had at least one odonate species, while none were recorded in seven out of 13 temporary ponds. According to the results of the multiple regression analysis, summarized in Table 3, the number of odonate species was primarily affected (positively) by the number of macrophyte species. Besides this, the depth appeared positively correlated with the species number, and this variable was in turn positively correlated with water duration, pond surface area and negatively correlated with nitrogen concentration (Table 2), all variables linked with the permanent status of the pond. In fact, several other models including variables correlated with depth were possible as a result of the multiple regression, all with similar $\mathrm{R}^{2}$. In the CCA plot the position of the "zero species " point was just along the positive part of the first axis where the increasing nitrogen vector was directed, while duration and macrophyte species number vectors were directed on the opposite part of the axis. So from CCA results too, we can conclude that the number of Odonata was positively related to macrophyte richness and with the permanent status of the pond and negatively with nitrogen concentration. Interestingly, the other environmental variables had no effect on the number of odonate species.

Table 3. Stepwise multiple regression of odonate species richness (after Log transformation) and environmental variables. Only macrophyte number of species (MS) and maximum depth (Zmax) (after Log transformation) are included in the model. All other variables were not significant. Model statistics: $\mathrm{N}=21, \mathrm{R}^{2}=0.784$, $\mathrm{F}=32.677, \mathrm{P}<0.0001$.

\begin{tabular}{lllll}
\hline Effect & Coefficient & S. E. & $\mathrm{t}$ & $P$ (two tail) \\
\hline Constant & -0.337 & 0.163 & -2.071 & 0.053 \\
MS & 0.051 & 0.108 & 44 & 0.000 \\
Zmax & 0.287 & 0.118 & 2.48 & 0.023 \\
\hline
\end{tabular}




\section{Odonate assemblage}

The data in Table 1 indicate that there were differences in odonate assemblage between permanent and temporary ponds. The four coenagrionid species Erythromma viridulum (Charpentier), Coenagrion scitulum (Rambur), Cercion lindeni (Sélys) and I. elegans were limited to permanent ponds, and we have already considered the presence of small coenagrionid larvae in temporary ponds as unsuccessful attempts at colonization. Anax imperator Leach, Orthetrum cancellatum Linnaeus, Orthetrum brunneum (Fonscolombe), Crocothemis erythraea (Brullé), Sympetrum striolatum (Charpentier) and Sympetrum fonscolombii (Sélys) were also limited to permanent ponds. In contrast, three species appeared to be limited to temporary ponds: Lestes barbarus (Fabricius), Lestes virens (Charpentier) and Sympetrum meridionale (Sélys), while another three $C$. viridis, Aeshna affinis Vander Linden and $S$. sanguineum were present both in the temporary and in the permanent ponds. So temporary ponds were populated only by Lestidae and Sympetrinae, with the exception of one species of Aeshnidae, A. affinis.

The CCA analysis showed that all species exclusively found in permanent ponds were in the negative part of the first axis, characterized by higher water duration (D) and number of macrophyte species (MS). The species inhabiting temporary ponds, on the other hand, showed different positions. Only L. barbarus and, less, $L$. viridis were in the positive part of the first axis, characterized by increasing nitrogen concentration $(\mathrm{N})$. The isolated position of L. virens and S. meridionale in the negative part of the second axis may have been due to the presence of these species in only one pond (CAT), whose position was is on the extreme negative part of the second axis.

\section{Discussion}

\section{Species richness and environmental variables}

Fewer species were recorded in the present study than in those carried out previously on lowland ponds of central Italy (Carchini et al. 2005), both in terms of the total number of species (16 vs 23 ) and of the mean species richness per pond $(2.9, \mathrm{SD}=2.02$ vs 7.9 , $\mathrm{SD}=1.64)$, even though the number of sampled ponds was similar, namely 21 and 23 respectively. This could be due to different sampling procedures, i.e. sampling of larvae or adults, respectively. There is, of course, a smaller probability of collecting larvae of a small population than of seeing a lone adult flying over the water. Another cause may be the fact that the 2005 study considered mainly permanent ponds, while in this study most of the sampled ponds were temporary. Indeed our results showed that the number of odonate species was lower in temporary ponds than in permanent ones. The positive correlation between water duration and the number of odonate species could be expected. To breed in temporary waters, species must have a survival strategy during the dry period. In the Mediterranean climate ponds are wet from winter to spring, and odonate species are not generally able to survive as adults until late autumn, when the ponds refill following rainfall (with the exception of Sympecma fusca (Vander Linden), which, however, lay eggs in spring). Therefore, species that breed in temporary autumnal ponds have an egg diapause and a rapid larval growth. They are limited to Lestidae and some Libellulidae and Aeshnidae, which are only a small proportion of the total odonate fauna. This study shows that odonate species richness also increased with aquatic macrophyte diversity. These findings confirm the results obtained in permanent ponds by previous papers regarding the importance of aquatic macrophytes, either their diversity (e. g. Sahlén 1999, Bazzanti et al. 2003) or their percentage cover (e. g. Carchini et al. 2005).

The CCA analysis also indicated a negative effect of increasing nitrogen concentration on the odonate species richness in agreement with a study of lowland ponds (Carchini et al. 2003) and of mountain ponds (Carchini et al. 2005), in which high levels of ammonium and phosphorus concentrations led to the absence of Odonata.

It is interesting that the presence of fish had no effect on odonate abundance or diversity, even though the presence of entomophagous fish is often highlighted as a key factor influencing the odonate fauna (e.g. Wildermuth 1994). This result agrees with that found by Carchini et al. (2003) on lowland ponds near Rome and by Carchini et al. (2005) on a set of mountain ponds. The majority of lowland ponds near Rome are populated only by Gambusia holbrooki Girard, whose small size and mainly planktonic feeding habits probably reduce both the predation on odonate larvae and the competition for food with them.

Furthermore, the pond area was not correlated to the number of odonate species. This finding is also quite intriguing, because the positive relation between habitat size and species number is well known (Houston 1994). We have contrasting results from other cited studies in central Italy, in which size had an effect in lowland ponds (Carchini et al. 2003, Bazzanti et al. 2003), but not in mountain ponds (Carchini et al. 2005). 
However, in the present study, several multiple regression models were possible, which did not completely exclude the potential influence of either area or other variables linked to the temporary-permanent status of the ponds on the number of odonate species. Indeed, wet phase duration was correlated with both pond surface area and maximum depth (see Table 2). As already described in a previous work on macroinvertebrate community hosted in the ponds studied (Della Bella et al. 2005), the effects of water permanence and pond size were difficult to separate and, therefore, size could be considered an alternative variable to explain the observed pattern of odonate species richness.

Neither shade nor land use proved to have an influence on the number of odonate species. These two characteristics were shown to have an influence in other studies (Moore 1991, Rith-Narajan 1998, Sahlén 1999, Bazzanti et al. 2003). However, two studies in central Italy agree with the present study (Carchini et al. 2003, Carchini et al. 2005), because neither shade nor the amount of forest surrounding the ponds appeared related to the odonate fauna. It is probable that the uniformity of conditions among the ponds studied here caused the absence of correlation of these two variables with odonate fauna.

\section{Odonate assemblage and environmental variables}

The species reported in the present study have all been recorded as adults in the Carchini et al. (2003) study on lowland ponds of central Italy. In contrast, they are different from the 14 species reported in the study of Carchini et al. (2005) on mountain ponds, except $C$. scitulum, $C$. lindeni, I. elegans, A. imperator, $C$. erythraea and $S$. fonscolombii that were common to both. The latter four are considered wanderers, migrants or pioneers (Schmidt 1978, Moore 1991, Corbet 1999).

The results of the present study show that the assemblage of odonate species was affected by water duration, the number of macrophte species and nitrogen concentration. In the temporary ponds three Lestidae, two Sympetrinae and one Aeshnidae were present. In fact, several species of European Lestidae and Sympetrinae are well known for breeding in temporary waters. In Europe, Aeshnidae are usually limited to permanent waters. However A. affinis had already been observed breeding in temporary ponds (Utzeri \& Raffi 1983). In our set of ponds, the temporary ones, except for one that was wet only for 60 days and was devoid of Odonata, were filled for four months or more, including the spring, a fact, as shown by Chovanec et al. (2003) from a temporary pond studied for five years, that is the key factor in allowing for the success of Lestidae populations. Despite this, several of our temporary ponds were lacking Lestidae. In the CCA plot there was not a complete differentiation between groups of permanent and temporary species: A. affinis, $S$. sanguineum and $L$. viridis have an intermediate position between the top-left corner, where "permanent" species are grouped, and the positions, far along the first and second axis, of the three species exclusive to temporary ponds. This disagrees with the results of a similar study on a set of Austrian temporary and permanent ponds (Schindler et al. 2003). Our results are probably due to the fact that there were as many species which were exclusive to temporary ponds as there were species which were present both in temporary and in permanent ponds.

Regarding the other variables influencing the presence of species in different ponds, the CCA showed the importance of macrophytes. This is not surprising as European Coenagrionidae and Aeshnidae need macrophytes for egg oviposition, while their larvae, as well as those of Lestidae and some Libellulidae live on the immersed branches of aquatic macropythes. Water duration and macrophytes were also shown for odonate assemblages in other studies outside the Mediterranean region (Schindler et al. 2003, David 2003). Our study added nitrogen concentration to these variables, in our study, in fact, L. barbarus only appeared to tolerate quite eutrophic conditions. Finally, several studies, in which a similar methodological approach was used, have shown that many of the environmental variables considered, if not all, had an influence on odonate assemblage (Garcia-Aviles et al. 1995, Bang 2001, Schindler et al. 2003). Two studies on the ponds of central Italy (Carchini et al. 2003, Carchini et al. 2005) in which CCA analysis was used also showed the influence of the majority of the considered environmental variables. We think that the fact that only three out of 17 environmental variables were included in the CCA model in the present study may be due to size of the data set, which was smaller than those of the two cited studies both in terms of the number of ponds and the number of species.

\footnotetext{
Acknowledgements

We wish to thank F. Grezzi for his valuable help in the field and laboratory work. G. Dowgiallo and A. Ruggiero were instrumental in the analyses of sediment and water samples, and $\mathrm{M}$. Iberite in the identification of macrophyte species. We are also grateful to the Presidential Estate of Castelporziano, WWF Lazio, Councils of Roma and Fiumicino, and Roma Natura for granting us permission to conduct our research within their natural reserves.
} 


\section{References}

Bang C. Jr. 2001. - Constructed wetland: high-quality habitat for Odonata in cultivated landscapes. Int. J. Odonatol., 4, 1-15.

Bazzanti M., Della Bella V. \& Seminara M. 2003. - Factors affecting macroinvertebrate communities in astatic ponds in central Italy. J. Freshwat. Ecol., 18, 537-548.

Briers R.A., Biggs J. 2003. - Indicator taxa for the conservation of pond invertebrate diversity. Aquat. Conserv. Mar. Fresh. Ecosyst., $13,323-330$.

Carchini G. 1983. - Odonati (Odonata).Guide per il riconos cimento delle specie animali delle acque interne italiane. Vol 21. Consiglio Nazionale delle Ricerche, Roma, 80 p.

Carchini G., Di Domenico M., Pacione T., Solimini A.G. \& Tanzilli C. 2003. - Species distribution and habitat features in lentic Odonata. Ital. J. Zool., 70, 39-46.

Carchini G., Solimini A.G., Ruggiero A. 2005. - Habitat characteristics and odonate diversity in mountain ponds of central Italy. Aquat. Conserv. Mar. Fresh. Ecosyst., 15, 573-582.

Chovanec A., Fels C. \& Kollar H.P. 2003. - Notes on the dragonfly community of a temporary pond near Vienna. Opusc. Zool. Flumin., 215, 1-9.

Cobolli M., De Matthaeis E., Utzeri C. \& Dell'Anna L. 1994. - Note preliminari sullo status tassonomico e la corologia italiana di Chalcolestes parvidens (st. nov.) (Odonata: Lestidae). Atti XVII Congr. Naz. Ital. Ent., Udine: 77-82.

Corbet P.S. 1999. - Dragonfly - Behaviour and Ecology of Odonata. Cornell University Press, Ithaca, 829 p.

David S. 2003. - Results of the monitoring of the dragonflies (Insecta: Odonata) in the catchment of Pariz stream. Ekologia, 22, 320-332.

Della Bella V., Bazzanti M. \& Chiarotti F. 2005. - Macroinvertebrate diversity and conservation status of Mediterranean ponds in Italy: water permanence and mesohabitat influence. Aquat. Conserv. Mar. Fresh. Ecosyst., 15, 583-600.

Garcia-Aviles J., Puig M.A., Soler A.G. \& Ferreras-Romero M. 1995. - An analysis of habitat distribution and associations in the Odonata of the Balearic Islands, Spain. Odonatologica, 24, 269-282.
Godreau V., Bornette G., Frochot B., Amoros C., Castella E., Oertli B., Chambaud F., Oberti D. \& Craney E. 1999. - Biodiversity in the floodplain of Saone: a global approach. Biodiv. Conserv., $8,839-864$.

Houston M.A. 1994. - The coexistence of species on changing landscape. Cambridge University press. Cambridge.

Moore N.W. 1991. - The development of Dragonfly communities and the consequence of territorial behaviour: a 27 year study on small ponds at Woodwalton Fen. Odonatologica, 20, 203-231.

Rith-Narajan J.C. 1998. - The influence of forest vegetation variables on the distribution and diversity of dragonflies in a Northern Minnesota forest landscape. Odonatologica, 27, 335-351.

Sahlén G. 1999. - The impact of forestry on dragonfly diversity in Central Sweden. International J. Odonatol., 2, 177-186.

Sahlén G. \& Ekestubbe K. 2001. - Identification of dragonflies (Odonata) as indicators of general species richness in boreal forest lakes. Biodiv. Conserv., 10, 673-690.

Schindler M., Fesl C., Chovanec A. 2003. - Dragonfly association (Insecta: Odonata) in relation to habitat variables: a multivariate approach. Hydrobiologia, 497, 169-180.

Schmidt E. 1978. - Odonata. Pages 274-279 in Limnofauna europea. Illies J. (ed.). Gustav Fisher Verlag, Stuttgart.

Solimini A.G., Della Bella V. \& Bazzanti M. 2005. - Macroinvertebrate size spectra of Mediterranean ponds with different hydroperiod length. Aquat. Conserv. Mar. Fresh. Ecosyst., 15, 601-611.

Utzeri C. \& Raffi R. 1983. - Observations on the behaviour of Aeshna affinis (Vander Linden) at a dried-up pond (Anisoptera: Aeshnidae). Odonatologica, 12, 141-151.

White J. \& Irvine K. 2003. - The use of littoral mesohabitats and their macroinvertebrate assemblages in the ecological assessment of lakes. Aquat. Conserv. Mar. Fresh. Ecosyst., 13: 331-351

Wiggins G.B., McKay R.J. \& Smith I.M. 1980. - Evolutionary and ecological strategies of animals in annual temporary pools. Arch. Hydrobiol. Suppl., 58, 97-206.

Wildermuth H. 1994. - Dragonfly and nature conservation: an analysis of the current situation in Central Europe. Adv. Odonatol., $6,199-221$. 